AROUEOLOGÍA Y SOCIEDAD

№ 28, 2013: 259-268

ISSN: 0254-8062

\title{
¿UN NUEVO PERFÍL PROFESIONAL? REFLEXIONES GENERALES ACERCA DEL ARQUEÓLOGO INDUSTRIAL EN EL SIGLO XXI
}

\author{
ÓSCAR GONZÁLEZ VERGARA* \\ UNIVERSIDAD DE MURCIA \\ oskarvergara@hotmail.com
}

\section{RESUMEN}

En este trabajo abordaremos el papel que ha de tener el arqueólogo industrial para abordar los aspectos patrimoniales contemporáneos desde una paradigma teórico y metodológico muy concreto: la Arqueología Industrial, o más concretamente, su evolución, la Arqueología Contemporánea. El mundo de la segunda mitad del siglo XX y del cambio al siglo XXI exige del arqueólogo industrial herramientas y metodologías que se sumen y amplíen a las ya usadas para el patrimonio de la revolución industrial. Nos encontramos en un momento muy propicio para regenerar una disciplina científica.

Palabras Clave: Arqueología Industrial, Arqueología Contemporánea, patrimonio industrial, patrimonio contemporáneo.

\section{Abstract}

This paper will discuss the role the industrial archaeologist needs to address contemporary heritage issues from a very specific theoretical and methodological paradigm: industrial archaeology or, more specifically, its evolution, contemporary archaeology. The world of the second half of the twentieth and twenty-first century requires from the Industrial archaeologist tools and methodologies that join and expand those already used with the heritage of the industrial revolution. This is a very favorable time to regenerate this scientific discipline.

KEYWORDS: Industrial Archaeology, Contemporary Archaeology, industrial heritage, contemporary heritage.

\section{INTRODUCCIÓN}

¿Debe la Arqueología estudiar el patrimonio reciente, contemporáneo? ¿Ello hace a esta disciplina ser intrusa con respecto a otras como la Historia Contemporánea, la Historia del Arte, la Arquitectura o la Antropología Sociocultural entre otras? ¿Qué debemos considerar por «arqueológico», "patrimonio», «reciente», o «contemporáneo»? ¿Sirven los conceptos y paradigmas usados hasta ahora o hay que matizarlos, darles nuevas acepciones y, llegado el caso, desecharlos por otros nuevos, mejores? De ser

* Licenciado en Historia y Master en Arqueología Aplicada (Universidad de Murcia). Actualmente, Doctorando en Arqueología (Universidad de Murcia) en la línea de investigación de Arqueología Industrial. Estudiante de Grado en Filosofía (Universidad Nacional de Educación a Distancia). 
posible analizar la sociedad contemporánea desde la mirada del arqueólogo, y sin que ello implique, a priori, cambiar todos los conceptos antes señalados, ¿cuáles serían las características del trabajo de ese arqueólogo? ¿Cuáles las herramientas y metodologías para investigar? ¿Cuáles las fronteras, repito, entre la Arqueología Industrial y el resto de disciplinas técnicas, humanas y sociales que estudian el patrimonio y la sociedad contemporáneos? Son muchas preguntas y pocas respuestas. A resolver estas preguntas entorno a la Arqueología Industrial en este milenio que empezó hace ya más de una década, dedicaremos gran parte de este trabajo.

Es nuestra voluntad mostrar que, de forma afirmativa, se puede y debe incluir a la Arqueología dentro del elenco, no poco numeroso, de ciencias y disciplinas que estudian lo contemporáneo. Es cierto que, en muchos aspectos, esta Arqueología Industrial y Contemporánea es «especial», algo diferente a la tradición arqueológica vinculada a otros periodos como el prehistórico o el romano, donde la Arqueología está muy cosolidada. La Arqueología Industrial y Contemporánea es algo más que la Arqueología de un periodo. Ello lo observamos muy bien si realizamos una lectura historiográfica del surgimiento y evolución de esta joven disciplina arqueológica. Pero tampoco es simplemente la Arqueología de una temática, como pudiera citarse la Arqueología de la Arquitectura, del Paisaje, de la Muerte, de la Religión y un largo etcétera. Es una Arqueología, repetimos, «especial», que es a la vez Arqueología de un periodo y de una temática, pero sería un error intentar reducirla a una sola de estas vertientes. Es, en fin, la disciplina que de forma más completa y global es capaz de analizar los diversos aspectos patrimoniales del mundo industrial y contemporáneo, traspasando las fronteras de una Arqueología vinculada sólo a lo material, y encontrando entre sus competencias el estudio de otras realidades como el patrimonio paisajístico y el inmaterial. Es una disciplina, por tanto, nueva, única en su especie, que sólo conservaría de «industrial» y de «arqueológico» la tradición que dio lugar a su nacimiento. Quizás sea más correcto, aunque no hay unanimidad, en llamar a esta disciplina Arqueología Contemporánea o Arqueología de las Sociedades Contemporáneas, pero usemos el nombre que usemos estamos poniendo en evidencia una postura epistemológica concreta, una forma de entender la Arqueología y una forma también de entender su trabajo. Continuemos.

\section{LA ForJa de un PERFiL: ArQueología Industrial (ARQueología Industrial 1.0)}

\section{Cuando el arqueólogo industrial no era arqueólogo ${ }^{1}$}

En este apartado mostraremos cómo era el arqueólogo industrial en aquella época, años 60, 70 y 80 del siglo pasado, en que la disciplina que conocemos como Arqueología Industrial era ejercida por arquitectos, ingenieros, historiadores del arte o historiadores general, de una forma aún más intensa que en la actualidad. Como todos saben, la Arqueología Industrial nace como disciplina en el Reino Unido de los años 50 de la mano de autores como Rix, Buchanan y Hudson, los «padres» de la Arqueología Industrial. Sus motivaciones eran las siguientes: tras la obsolescencia tecnológica, los grandes avances técnicos y la necesidad de renovación y mejora del tejido arquitectónico y urbanístico ligado a la industria y el proceso de industrialización, numerosas fábricas, puentes, minas, estaciones de ferrocarril, etc., empezaron a valorarse como «estorbos», o mejor dicho, como límites del progreso del Reino Unido renaciente después de las dos Guerras Mundiales. El mundo se había mostrado, para el siglo XX, sobre todo pasado su ecuador, lleno de posibilidades nuevas. Los avances tecnológicos, científicos, muchos de los cuales puestos en práctica en las Guerras Mundiales, daban la posibilidad de reformar de forma global el sistema industrial que había caracterizado a la industria inglesa de época colonial. El ferrocarril y las máquinas de vapor, por poner solo unos ejemplos, estaban en desu-

1 Sirva de introducción a la historiografía de esta disciplina los siguientes trabajos recogidos en el apartado bibliográfico de Aguilar Civera, Cerdà Pérez, Vicenti Partearroyo, Cano Sanchiz, Casado Galván y González Vergara. 
so tras el transporte terrestre movido por motores de combustión, la electricidad y el traslado de las fábricas a espacios más desabitados, etc. Ello generó una ingente cantidad de espacios y de edificios, representantes de la Revolución Industrial inglesa y de su pasado glorioso, patriótico y victoriano, que corrían el peligro de ser destruidos ante los avances del progreso. Muchos colectivos sociales, con anterioridad a los colectivos académicos, vieron la necesidad de documentar, describir y poner en valor estos «monumentos» del pasado glorioso y reciente inglés, el industrial, pero no existía una disciplina que abarcara todas las variables que más tarde se consideraron necesarias para un buen estudio sobre patrimonio industrial. De esa urgencia social nació una disciplina que poco a poco fue considerándose científica y académica: la Arqueología Industrial.

Estos «padres» realizaron una importantísima labor de documentación y registro en catálogos del patrimonio que se estaba perdiendo. Y este proceso se dio también, en muchos casos a imitación del modelo inglés, en Alemania, Francia, Italia o España, si bien en este último bastante más tarde. En los casos más emblemáticos consiguieron proteger fábricas, estaciones de ferrocarril o puentes, bien como museos, bien como edificios y otros espacios «refundados». Son características de estos albores de la Arqueología Industrial el no ser estudiada por arqueólogos (mucho menos especialistas en patrimonio industrial y contemporáneo), favorecer el registro, documentación, descripción y puesta en valor de los monumentos del pasado industrial (fábricas, estaciones de ferrocarril, puentes) y no las también necesarias labores de análisis e interpretación. Tampoco se llevó a cabo este proceso de forma sistemática y científica; una verdadera Arqueología, tal y como la conocemos hoy, pues no se puede llamar Arqueología a algo que solo es descripción y registro. Esto nos hace recordar la Arqueología de los monumentos y los coleccionistas. Esta situación poco a poco fue cambiando conforme la disciplina se expandió por Europa (Francia, Alemania, Italia, y más tarde a España y Portugal), así como por el resto del mundo; poco a poco se fue haciendo más científica y arqueológica.

La situación cambió de forma sustancial en los años ochenta, noventa y con el cambio de siglo y de milenio. La Arqueología perfeccionó dos herramientas o metodologías de muy alta aplicabilidad en un patrimonio, como el industrial y contemporáneo, donde la excavación clásica es inexistente, excusa esta que hacía que la comunidad científica no viera la necesidad de arqueólogos contemporáneos para un patrimonio donde no se excava. Esas dos metodologías son la prospección espacial y la estratigrafía muraria, respaldadas teóricamente por la Arqueología de la Arquitectura y la del Paisaje, que permitían al arqueólogo erigirse como un especialista capaz de estudiar de forma arqueológica edificios ligados a la Era Industrial y el mundo contemporáneo, que antes eran sólo objeto de arquitectos, ingenieros e historiadores del arte, y paisajes industrializados, objeto anteriormente de geógrafos o geólogos. El arqueólogo se fue introduciendo en la fábrica².

\section{Un nuevo profesional arqueólogo para una nueva arqueología: los arqueólogos en la fábrica}

Retomando lo anteriormente dicho, si en la segunda mitad del siglo xx se vieron las necesidades de una Arqueología de lo Industrial, y cómo fue a finales del siglo xx y principios del xxI cuando se asumieron, asentaron y promovieron herramientas y metodologías arqueológicas (Arqueología de la Arquitectura y Arqueología del Paisaje) que permitían al arqueólogo «excavar la fábrica», con los cambios económicos, tecnológicos y científicos del último tercio del siglo XX en adelante, hoy vemos que la Arqueología Industrial se queda «corta» ante las realidades patrimoniales de la sociedad contemporánea (y aquellas industriales y contemporáneas que no entraban dentro del concepto de «patrimonio industrial» en los primeros momentos de la disciplina), y que rebasan los límites de fábricas, estaciones de ferrocarril, minas, etc. La sociedad industrial dejó otros patrimonios que los primitivos arqueólogos industriales no estudiaron como los productos producidos en cadena (por ejemplo, me-

2 «Arqueólogos en la fábrica» es parte del título sugerente, e interesante artículo, escrito por Cano Sanchiz (2007) que trata la historiografía de la disciplina y que recogemos en el apartado bibliográfico. 
naje, indumentaria, etc.), viviendas, escuelas, espacios rurales, espacios religiosos, etc. La Arqueología Industrial debía asumir también esa realidad patrimonial no industrial, pero sí contemporánea, añadiendo el patrimonio cultural no estrictamente material y el del presente. ¿Dejaba esta nueva Arqueología Industrial de ser Arqueología y de tener como temática lo Industrial? En parte sí, en parte no. Pero la Arqueología Industrial, como se ha podido consensuar internacionalmente (ver Carta de Nizhny-Tagil de 2003), es una Arqueología «especial» y diferente al resto de arqueologías pues ha de aunar en su método las metodologías arqueológicas y otras que le sirvan para la documentación, análisis, interpretación y puesta en valor del patrimonio contemporáneo, ya no sólo el industrial. Deben ser competentes sus profesionales en muchos ámbitos variados como el de la arquitectura o la ingeniería, saber desenvolverse en archivos, saber extraer datos de las fuentes iconográficas, etc. No es de extrañar que se afirme que, dentro de las ciencias humanas y sociales que estudian la realidad patrimonial contemporánea, la Arqueología Industrial ha de ser una disciplina especializada que forme, desde la Arqueología pero en constante colaboración con arquitectos, historiadores, ingenieros, geógrafos, antropólogos, etc., arqueólogos industriales-contemporáneos, especialistas en el estudio patrimonial de los restos culturales (materiales, inmateriales y paisajísticos), ligados a la Era Industrial y la Sociedad Contemporánea. Ello necesita, pues, una nueva Arqueología Industrial y una nueva concepción del arqueólogo industrial. Pero en los apartados siguientes profundizaremos un poco más en estos aspectos.

\section{Metodología y herramientas del arqueólogo industrial ${ }^{3}$}

Como ha venido señalándose anteriormente, el arqueólogo industrial comparte herramientas y metodologías con otras disciplinas sociales y humanas. Por ejemplo, de la Arqueología tradicional ha tomado principalmente dos formas de actuar sobre el patrimonio: la Arqueología de la Arquitectura y la del Paisaje, grosso modo, la prospección espacial y la estratigrafía muraria, sin olvidar que, como en otras épocas, la Arqueología Industrial ha de estar capacitada para interpretar de forma arqueológica todas las realidades de la sociedad.

Ante la necesidad de documentar, analizar e interpretar el patrimonio de época contemporánea (material, inmaterial y paisajístico), el arqueólogo industrial ha de ser también un poco historiador y antropólogo, es decir, ha de tener competencia y habilidad para buscar e interpretar un patrimonio compuesto de fuentes escritas repartidas en una infinitud de archivos, públicos y privados, y de la más diversa índole. Es un patrimonio compuesto en gran parte de recuerdo, música, literatura, etc., lo que hace necesario una formación en antropología sociocultural que ayude a descifrar esos códigos todavía no fosilizados por el tiempo, en muchos aspectos pertenecientes todavía a individuos vivos, y donde la historia al uso se queda corta.

En fin, no hemos de olvidar que la realidad patrimonial contemporánea, y su contexto sociocultural e histórico, implican conocimientos y diálogos con otras ciencias y sus métodos como la Arquitectura, la Ingeniería, la Geografía, la Economía, la Historia del Arte, etc. Es la Arqueología Industrial, en su definición y en su metodología, necesariamente inter y multidisciplinar. Por ello, ante la necesidad de metodologías y herramientas muy específicas, ha de ser un arqueólogo especializado en el mundo contemporáneo y sus fuentes.

3 Casado Galván desmenuza, en 2009, en varios artículos, las diversas fuentes, y por tanto metodologías, que componen la Arqueología Industrial. Igualmente, el resto de obras señaladas en la bibliografía abordan, de manera directa e indirecta, las fuentes y metodologías de la disciplina. 


\section{¿ES POSIBLE UNA ARQUEOLOGÍA POSTINDUSTRIA O CONTEMPORÁNEA? (Arqueología Industrial 2.0)}

\section{Características de la Arqueología Contemporánea (Arqueología Industrial 2.0)}

Tres son los grandes patrimonios que ha de estudiar la clásica Arqueología Industrial hoy si quiere dejar de ser la incompleta arqueología del monumento industrial: el material, el inmaterial y el paisajístico; lo que hace que la Arqueología Industrial asuma la Arqueología de la Arquitectura (estratigrafía muraria; excavación de edificios y estructuras construidas), la Arqueología del Paisaje (prospección del territorio; excavación del paisaje) y la Antropología Sociocultural, además de otras herramientas y metodologías procedente de otras disciplinas. Sin ello, seguiremos haciendo una Arqueología Industrial a medias. Por las características del mundo y la sociedad contemporáneas, sobre todo por la abundancia de fuentes (no sólo las materiales), el arqueólogo industrial es un arqueólogo algo especial, pues a su labor de arqueólogo ha de unir muchas veces la de historiador, antropólogo, economista, geógrafo, arquitecto o ingeniero, sin olvidar que no es su labor suplantar estos otros campos del saber, pero sí consciente de ser éste, el arqueólogo industrial, el máximo especialista del patrimonio cultural de época industrial y contemporánea. Estos aspectos ya los hemos señalado anteriormente pero es necesario ahondar un poco más y dejar sentado de una vez por toda qué es la Arqueología Contemporánea y sus diferencias con la Arqueología Industrial tradicional.

Con los cambios de método y con la creación de una disciplina específica y de un profesional específico para el estudio del patrimonio contemporáneo estamos en condiciones de afirmar, así, que la renovación de la Arqueología Industrial (1.0) será un hecho a favor de otra (Arqueología Contemporánea o Arqueología Industrial 2.0) con las siguientes características y retos: 1. Amplitud del patrimonio estudiado; 2. Amplitud del espacio cronológico estudiado; 3. Amplitud de las herramientas y métodos utilizados; 4. Mayor teorización y reflexión epistemológica sobre la disciplina; 5. Difusión social de los resultados y de la necesidad de una disciplina específica para el estudio de lo industrial y contemporáneo en su vertiente patrimonial; 6 . Necesidad de un profesional especializado; y, finalmente, 7. Necesidad de apoyo por parte de las universidades, las administraciones políticas y demás espacios e instituciones de investigación, patrimonio y educación que dejen espacio para los estudios de arqueología industrial dentro de los proyectos de investigación y planes de estudio a todos los niveles, sobre todo la inclusión de la Arqueología Industrial como especialidad universitaria y profesional.

\section{Fronteras entre la Arqueología Industrial y la Postindustrial/Contemporánea. ¿Fronteras en- tre Arqueología Industrial 1.0 y Arqueología Industrial 2.0?:}

Con una Arqueología Industrial entendida como Arqueología Contemporánea (o Arqueología Industrial 2.0), se rompen las estrechas fronteras que con anterioridad separaban los campos de estudios de muchas disciplinas. Se ha dicho que uno de los problemas que impidió e incitó a los arqueólogos a no estudiar el patrimonio industrial era que, aún siendo material, no se necesitaba de la excavación. La Arqueología se consideraba, más que una disciplina (el estudio de los restos humanos a partir de los restos materiales) un método (excavación). De ahí que, hasta que la propia Arqueología no asumió otros métodos alternativos a la clásica excavación, como supusieron los métodos de la estratigrafía muraria y la prospección paisajística, la Arqueología no pudo, ni quiso, tomar en serio los estudios sobre el patrimonio cultural contemporáneo.

De igual forma, hoy vemos que las fronteras que separan, en los estudios sobre el patrimonio contemporáneo, al historiador (en las vertientes social, económica, científico-técnica, de la arquitectura, de la ingeniería, del arte, etc.), al antropólogo, al arquitecto, al ingeniero, al sociólogo, etc., no son tan fuertes como antaño. En un mundo global como el nuestro, lleno de especialidades, y con un patrimonio documentable de muchas formas distintas, se necesita la ayuda y cooperación de muchas discipli- 
nas juntas. ¿Qué lugar queda para la Arqueología Industrial, aún la reformada? No ha de limitarse ni a sólo estudiar patrimonio arquitectónico, o los monumentos de lo industrial, ni pretender hacer todas las labores de documentación, análisis, interpretación y puesta en valor. Su labor será especializarse en las características de la sociedad contemporánea, a los tipos y formas de documentar esa sociedad en sus aspectos patrimoniales, entender los contextos socioculturales, ecónomos, políticos, científicos, etc., que se desprenden de esos patrimonios, y aplicar las herramientas y metodologías para el estudio de los tres patrimonios contemporáneos: el material, el inmaterial y el paisajístico. Ello hace que, necesariamente, el arqueólogo industrial o arqueólogo contemporáneo tenga conocimientos de todas las disciplinas anteriormente mencionadas pero sin ser de forma plena ni historiador, ni antropólogo, ni mucho menos arquitecto, ingeniero o economista. Será, más que ningún otro, quien mejor comprenderá el patrimonio contemporáneo que se trae entre manos, si bien nunca tendrá, ni lo necesita, la precisión técnica del ingeniero o del arquitecto en cuanto a edificios y estructuras se refiere; no podrá ser tan diestro y preciso como el geógrafo o el geólogo para analizar la forma en la que el hombre y el medio se relacionan; ni podrá, para terminar, suplantar al antropólogo en su mirada sociocultural del patrimonio inmaterial contemporáneo.

El arqueólogo industrial no es ni arquitecto, ni historiador, ni ingeniero, ni geógrafo ni antropólogo, y quizás ni siquiera sea arqueólogo. Si anteriormente era una necesidad hacer del profesional del patrimonio industrial un arqueólogo, quizás hoy sea necesario poner a la Arqueología al mismo nivel que las otras ciencias y disciplinas antes mencionadas, y que lo que pretendemos llamar Arqueología Industrial y Contemporánea sea, precisamente, otra cosa. Pero ello generaría más problemas que ventajas a la situación actual y ello por varias razones. Una, existe, afortunadamente, cierto calado social, académico y político de la existencia de una Arqueología Industrial que se encarga, grosso modo, de estudiar edificios, fábricas, medios de transporte, y demás restos patrimoniales recientes, incluidos el paisajístico y el inmaterial. El otro problema es que no existe nombre para esa supuesta nueva disciplina que aunará las demás herramientas y métodos en el estudio de lo contemporáneo, y que no lleve la coletilla de arqueología de, historia de, antropología de... Por ello, la Arqueología Industrial 2.0 tiene de arqueología y de industrial sólo el nombre, pues ni es característico de su método hoy sólo el procedente de la arqueología, ni es su fin el estudio de los espacios industriales de época industrial. Muy al contrario, usa métodos procedentes de muchas disciplinas técnicas, sociales y humanísticas, y es su fin estudiar toda realidad patrimonial (material, inmaterial y paisajística), así como los contextos socioculturales, económicos, ideológicos, políticos, etc., de las sociedades que van, grosso modo, desde las revoluciones industriales a los procesos de construcción de una sociedad contemporánea como la nuestra, caracterizadas por aspectos como el capitalismo, la globalización, y no tanto el tener una industrialización fuerte.

Esta forma «nueva» de concebir la Arqueología Industrial nos posibilita estudiar, para épocas como la de los siglos XIX y XX, no sólo los clásicos monumentos de antaño (fábricas, estaciones de ferrocarril o puentes), sino también espacios no industriales compuestos de edificios de arquitectura doméstica, religiosa, pública, y otros elementos no arquitectónicos necesariamente como son los olvidados patrimonio rural, fuentes de energía, obra pública, comunicaciones, patrimonio inmaterial y paisajístico, etc. Además, ante los procesos de postindustrialización (y hasta de desindustrialización) y la introducción de forma masiva de tecnologías como la de Internet, aparatos digitales, etc., esta nueva disciplina tiene la legitimidad y la necesidad de abordar el estudio del patrimonio característico de nuestra sociedad contemporánea, fomentar desigualdades a la hora de elegir qué patrimonio y desde qué óptica estudiar lo industrial y contemporáneo. Si se admite la existencia de una Historia del Tiempo Presente ¿no es posible una Arqueología del Tiempo Presente? Concluyamos.

Ha de considerarse el patrimonio industrial y contemporáneo como un todo, y no un patrimonio sesgado ni separado de otro más amplio. Ello quizás era posible en otras épocas donde, epistemológicamente, era más «fácil» separar disciplinas y patrimonios según el estudioso que se encargara de 
ellos y sus particulares posturas. Aunque ello, realmente, no ha hecho que la Historia y la Arqueología, por poner dos ejemplos notables, se entremezclaran al compartir aspectos patrimoniales. Y un patrimonio como el industrial y el contemporáneo entendido de una forma general ha de procurar espacios para todos los especialistas, y también para el arqueólogo industrial como el máximo especialista y el de mayor competencia tiene ante esta nueva forma de concebir el patrimonio contemporáneo. Pero para que el arqueólogo contemporáneo pueda erigirse como ese máximo especialista del patrimonio industrial ha de tener una formación y una serie de competencias que lo capaciten para saltar de patrimonio en patrimonio, poder dialogar con los especialistas y técnicos, y poder comprender de forma completa y holística el rico, variado y complejo patrimonio contemporáneo. Para ello, unos aspectos generales en el apartado siguiente.

\section{Herramientas para un nuevo perfil profesional}

El elenco de herramientas y metodologías necesarias para que el arqueólogo industrial, más aún el que trabaje desde la antes llamada Arqueología Industrial 2.0 o Arqueología Contemporánea, ha de ser variado y preciso. Muchas de estas herramientas y metodologías ya las hemos tratado, pero conviene recogerlas y desarrollarlas un poco más.

Ante una Arqueología que precisa el conocimiento y capacidad de muchas fuentes (escritas, arquitectónicas, paisajísticas, historia oral, toponimia, patrimonio inmaterial, etc.), las herramientas básicas del arqueólogo industrial serán:

1. La Arqueología de la Arquitectura: esta herramienta o metodología le hará ser capaz de realizar estratigrafías de muros, estudiar la historia de la arquitectura y la construcción en general, ser consciente de la importancia y evolución de los materiales y tipologías empleados para la edificación, los sistemas de trabajo empleados, los usos y tipos de edificios empleados en época contemporánea e industrial, etc. Le aportará información para analizar la evolución en usos y técnicas edilicias de un conjunto arquitectónico, la procedencia, por ejemplo, de los materiales empleados, la decoración de sus fachadas e interiores, etc. Es la disciplina que más contacto proporciona al arqueólogo industrial con los especialistas de la construcción: arquitectos, ingenieros e historiadores de la arquitectura.

2. Arqueología del Paisaje: en la doble vertiente de prospección (metodología arqueológica) y el estudio de las relaciones hombre-paisaje. Si se parte de la premisa de que el paisaje informa al arqueólogo, y a cualquier otro estudioso interesado en el tema, de cómo el hombre vive, usa y piensa el paisaje, no podemos olvidar que, ante una sociedad como la industrial y contemporánea, con grandes explotaciones industriales (minas por ejemplo), comunicaciones (redes de carreteras, ferrocarriles, macropuertos, grandes pistas para transporte aéreo, etc.), el fenómeno de las macrourbanizaciones, macroespacios de ocio, etc., la forma que presentan estos espacios nos habla mucho sobre la tecnología y forma en que en época reciente actuamos sobre el territorio. Esta especie de Arqueología Geográfica es la que, precisamente, pone en contacto al arqueólogo industrial con geógrafos, geólogos, urbanistas, expertos en medioambiente, etc., pues además se encargará del estudio de las consecuencias del uso masivo del espacio y se su explotación: la contaminación, y del eterno debate de qué tiene más prioridad, regenerar espacios contaminados y altamente alterados por la industria y la sociedad contemporáneas, o si es preciso considerarlos «macrovertederos» y contemplarlos como parte del patrimonio cultural a proteger.

3. Una línea de trabajo que va adquiriendo mucha presencia en los estudios sobre el patrimonio cultural contemporáneo tiene un marcado perfil ingeniero, aunque en parte es la asunción o fusión de las dos metodologías anteriores. Me refiero al estudio por parte de la Arqueología Industrial de la obra pública, el transporte y las comunicaciones, así como los medios de producción y transporte de la energía. Serían unas herramientas que permiten al arqueólogo industrial estudiar 
embalses, presas hidráulicas, fábricas de luz, torres telégrafos, faros, puertos, etc., y que son la evolución natural a los clásicos estudios sobre puentes metálicos y ferrocarriles, tan estudiados en los albores de esta disciplina. Supone, más que las dos metodologías anteriores, conocer la historia de la ciencia y la técnica de época contemporánea, los sistemas de transporte y generación de energía y la variedad de elementos patrimoniales que generan.

4. El arqueólogo industrial debe, mucho más que el anterior, tener competencia y habilidades de historiador. Parte de la documentación que informa sobre los restos materiales y paisajísticos que estudia están en archivos y en una infinidad de fuentes escritas. Ha de saber buscar en archivos, privados y públicos, ser capaz de leerlos, analizarlos y trabajar con ellos. Si en el pasado hemos visto cuán necesaria es la formación histórica para el arqueólogo, para tiempos recientes, donde la mayoría de la información está presente, dicha formación es vital.

5. A lo anteriormente dicho hay que añadir que gran parte de la información está todavía en la memoria de las personas que vivieron y trabajaron los entornos que estudiamos. Es necesario recurrir a la historia oral, la etnografía y la sociología para extraer esa información, sistematizarla, y volcarla en la documentación ya sistematizada. Nos referimos a historia de vida, al patrimonio inmaterial (música, literatura popular, etc.), folklore, etc.

6. Y para terminar, no vendría nada más asumir herramientas y métodos de estudio de la historia del arte, no sólo para los aspectos arquitectónicas, sino también para el análisis de otros aspectos menos llamativos como la vestimenta, música, el cine, la fotografía, etc., fuentes estas dos últimas vitales y ventajosas para el estudioso del patrimonio industrial. Por primera vez en la Historia tenemos la posibilidad de ver, de forma estática o en movimiento, edificios y espacios en uso, saber cómo se usaban ciertas herramientas, etc., cuestión esta que se ve agrandada cuando a la imagen se le añade sonido.

\section{Algunas CONSIDERACIONES FINALES}

Teníamos como un objetivo primordial el mostrar, a lo largo de estas páginas, un breve resumen comentado sobre la necesidad de refundar una disciplina que hace relativamente poco vio la luz y que ha tenido una trayectoria llena de luces y sombras. Las luces han sido, por ejemplo, despertar al mundo y a la sociedad sobre un patrimonio cultural contemporáneo que estaba siendo víctima del progreso $\mathrm{y}$, a diferencia de otros patrimonios culturales del pasado (prehistórico, clásico, medieval, moderno), ni siquiera se contemplaba la posibilidad de su estudio y puesta en valor. Surgió ante la necesidad de proteger un patrimonio en peligro, y sirvió con creces a esa necesidad. Años y décadas posteriores, la disciplina ensombreció, victima del monumentalismo del que hizo gala en sus primeros años y quedó, durante décadas, vinculada a arquitectos, ingenieros e historiadores del arte que veían en la Arqueología Industrial la disciplina especialista en la edificación y maquinaria de la industria contemporánea. Se crearon hasta asignaturas y especialistas formados en escuelas de arquitectura e ingeniería, y en otras facultades como en las de historia del arte. Pero pronto se vio que relacionar la Arqueología Industrial sólo con la obra edilicia y ceder esta materialidad a estos tres especialistas y negar el resto de patrimonios que componen el patrimonio cultural contemporáneo significaba renunciar a lo que de arqueológico tenía la disciplina (aunque fuera solo el nombre) y poner trabas a su propia evolución. La gran excusa para no hacer de la Arqueología Industrial disciplina del arqueólogo era que para nada servía este último especialista si en este patrimonio en cuestión no excavaba. Quizás este ha sido la gran sombra de la Arqueología Industrial, el negarle el uso del método arqueológico para el estudio del patrimonio industrial al considerar que, al ser un patrimonio en pie, de nada servían los arqueólogos. Curioso que, con un pensamiento de esta índole, se le puso sin reparos al estudio de los monumentos de la industrialización la coletilla de «arqueología». Algo de verdad tienen estas críticas, pues el patrimonio industrial ha despertado el interés de los arqueólogos en una época muy reciente, quizás fomentada por la inclusión dentro del método arqueológico de alternativas no extractivas 
como la prospección (y la Arqueología del Paisaje) y la estratigrafía muraria (así como la Arqueología de la Arquitectura). La Arqueología fue, con el paso del tiempo, algo más que sacar tierra de un terreno, y cuando se añadieron a la metodología de excavación las alternativas no extractivas, ya no había excusas para una Nueva Arqueología Industrial trabajada por arqueólogo y con los fines propios de la Arqueología, ayudando a comprender mejor la realidad histórica, cultural, social, económica, etc., de la sociedad contemporánea a través de su patrimonio, un patrimonio que además de material es también inmaterial y paisajísticos. Ni los arqueólogos podían negarse a estudiar un patrimonio para el que disponían de metodología sin necesidad de excavar, ni los arquitectos, ingenieros ni historiadores podían obstaculizar la necesaria introducción de la Arqueología en las fábricas.

Nacía así una Arqueología Industrial arqueológica pero con unas premisas muy distintas a la de la Arqueología tradicional pues, a las labores meramente materiales, el arqueólogo industrial ha de estar capacitado para hacer investigación sobre fuentes escritas, cartográficas, iconográficas, etc. (y aunque esto es tradicional en las demás Arqueologías, Prehistóricas e Históricas, se hace más importante, abundante y complejo en el patrimonio reciente), saber desenvolverse con fuentes, herramientas y metodologías de muy variada procedencia y características y, en fin, servir de máximo especialista sobre el patrimonio cultural contemporánea. Proponemos que es hora de, asumidas las ventajas del método arqueológico, esta Arqueología Contemporánea vaya más allá, y quizás sea necesario un cambio de nombre. Y si a esta disciplina no se la llama de otra forma es, insistimos, porque no existe ese otro nombre, no puede ser encuadrado en ninguna disciplina existente y, sobre todo, porque no se puede hacer olvidar la trayectoria de unos estudios sobre el patrimonio cultural contemporáneo que, con sus luces y sombras, aunque con poca importancia entre los arqueólogos, ha sido en cambio muy importante entre arquitectos, ingenieros, historiadores del arte y otros especialistas.

Así, esperamos, en este siglo XXI que se presenta igual o más incierto que el xx, resuelva los problemas de su patrimonio contemporáneo atendiendo a las disciplinas humanas y culturales como la Arqueología, la Historia (en todas sus variedades), la Geografía y la Antropología, promueva más proyectos y actividades sobre el patrimonio cultural contemporáneo, se realicen cursos, seminarios y masters que fomenten la formación de arqueólogos industriales profesionales, y ver nacer así, de una vez por todas, la necesaria Arqueología Industrial 2.0. El futuro de la Arqueología Industrial pasa por transformarse en Arqueología Contemporánea y seguir transformándose aún más. O sencillamente, de rendir esta Arqueología a la sistematización y especialización temporal y distinguir por un lado la Arqueología Industrial para referirnos al análisis arqueológico de la sociedad industrial, y por otro la Contemporánea, siendo esta última una especie de Arqueología del Tiempo Presente, de la Desindustrialización, de la Postindustrialización, etc. Pero ello carece de sentido pues la sociedad de hoy es a la ver heredera y desarrolladora de la industrial. Hay muchos aspectos que difieren, pero otros que se mantienen.

Y llegados a este punto, lo más sano y lógico sería dejar que Clío y Cronos, como divinidades e inspiradores de la Historia y del Tiempo, juzguen en el futuro si era necesario en este nuestro humilde presente una disciplina arqueológica distinta a la que veníamos llamando Arqueología Industrial, o una evolución-continuación de la misma. Los investigadores del futuro, esperamos, tendrán la respuesta. 


\section{BibliogRAFÍA}

AGUILAR, Inmaculada

1998 Arquitectura Industrial: concepto, método, fuentes. Museu d'Etnologia. Valencia.

CANO, Juan

2007 «Arqueólogos en la fábrica. Breve recorrido por la historiografía de la Arqueología Industrial». SPAL. Revista de Prehistoria y Arqueología de la Universidad de Sevilla, № 16: 53-67.

CASADO, Ignacio

2009 «Introducción a la Arqueología Industrial: origen de la disciplina y metodología». Contribuciones a las Ciencias Sociales (Universidad de Málaga). [En línea] <http://www.eumed.net/rev/cccss/06/ icg12.htm> [Acceso el 7 de marzo de 2013].

2009 «La Arqueología Industrial: una investigación multidisciplinar». Contribuciones a las Ciencias Sociales (Universidad de Málaga). [En línea] <http://www.eumed.net/rev/cccss/06/icg18.htm> [Acceso el 7 de marzo de 2013].

2009 «La arquitectura de la industrialización». Contribuciones a las Ciencias Sociales (Universidad de Málaga). [En línea] <http://www.eumed.net/rev/cccss/06/icg9.htm> [Acceso el 7 de marzo de 2013].

2009 "Caracterización histórica del concepto de industria». Contribuciones a las Ciencias Sociales (Universidad de Málaga). [En línea] <http://www.eumed.net/rev/cccss/06/icg27.htm> [Acceso el 7 de marzo de 2013].

2009 «Fuentes escritas, orales e iconográficas de la Arqueología Industrial». Contribuciones a las Ciencias Sociales (Universidad de Málaga). [En línea] <http://www.eumed.net/rev/cccss/06/icg11.htm> [Acceso el 7 de marzo de 2013].

2009 «Fuentes materiales de la Arqueología Industrial». Contribuciones a las Ciencias Sociales (Universidad de Málaga). [En línea] <http://www.eumed.net/rev/cccss/06/icg13.htm> [Acceso el 7 de marzo de 2013].

2009 «Breve historia de la protección del patrimonio industrial». Contribuciones a las Ciencias Sociales (Universidad de Málaga). [En línea] <http://www.eumed.net/rev/cccss/06/icg4.htm> [Acceso el 7 de marzo de 2013].

CERDÀ, Manuel

2008 Arqueología industrial: teoría y práctica. Valencia: Universidad de Valencia.

GONZÁLEZ, Óscar

2009-2010 «Arqueología Industrial. Un comentario bibliográfico tras medio siglo de historiografía». Anales de Prehistoria y Arqueología de la Universidad de Murcia, № 25-26: 275-300.

2011 «Conociendo el pasado industrial. Perspectivas desde la arqueología». Ab Initio. Revista de estudiantes de Historia, № 3: 165-197. [en línea] <http://www.ab-initio.es/pagPdf/numero3/0309-ARQUEOLOGIA.html> [Acceso el 7 de marzo de 2013].

2011 Patrimonio minero e industrial en la Sierra Minera de Cartagena-La Unión. Introducción a su estudio y puesta en valor desde la Arqueología Industria. Trabajo Fin de Máster. Universidad de Murcia [sin publicar].

2012 Arqueología Industrial en La Unión (Murcia). Patrimonio y paisaje de una ciudad minera. Tesis de Licenciatura. Universidad de Murcia [sin publicar].

THE INTERNATIONAL COMMITTEE FOR THE CONSERVATION OF THE INDUSTRIAL HERITAGE

2003 Carta de Nizhny-Tagil sobre el Patrimonio Industrial. [En línea], <http://international.icomos. org/18thapril/2006/nizhny-tagil-charter-sp.pdf> [Acceso el 12 de marzo de 2013].

VICENTI, Ana

2007 «Perspectivas sobre la Arqueología Industrial». Arqueoweb. Revista sobre Arqueología en Internet (Universidad Complutense de Madrid), № 9 (1): 1-49. [En línea] <http://pendientedemigracion. ucm.es/info/arqueoweb/pdf/9-1/vicenti.pdf > [Acceso el 7 de marzo de 2013]. 